\title{
A ARGUMENTAÇÃO NO GÊNERO DISCURSIVO CONTRATO: UMA ANÁLISE DOS MODALIZADORES DEÔNTICOS
}

\author{
THE ARGUMENTATION IN THE GENRE DISCURSIVE \\ CONTRACT: AN ANALYSIS OF THE DEONTIC MODALIZATION
}

Kátia Regina Gonçalves de Deus ${ }^{1}$

Erivaldo Pereira do Nascimento ${ }^{2}$

\begin{abstract}
RESUMO
A presente pesquisa tem como objetivo analisar e descrever o funcionamento semânticoargumentativo dos modalizadores deônticos no gênero discursivo Contrato, cuja finalidade é estabelecer um acordo entre pessoas que transferem, uma para a outra, determinados direitos ou se sujeitam a obrigações. A fundamentação teórica adotada neste trabalho tem base nos estudos sobre a Modalização Discursiva, apresentada por Lyons (1977), Cervoni (1989), Koch (2009), Castilho e Castilho (1993), Neves (2010), Nascimento e Silva (2012), entre outros, bem como na Teoria dos Gêneros Discursivos proposta por Bakhtin (2000 [1979]). Além desse aporte, também se fundamenta na Teoria da Argumentação na Língua, proposta por Ducrot e colaboradores (1988). O corpus é composto por 10 (dez) contratos que foram coletados em instituições públicas e privadas, além da rede mundial de computadores. Essa investigação é de natureza quali-quantitativa, de cunho descritivo e interpretativista, visto que foi descrito o funcionamento semânticoargumentativo dos modalizadores deônticos e os efeitos de sentido provocados por sua utilização nos textos objetos de investigação. O referencial adotado permitiu compreender como esses modalizadores funcionam estrategicamente nesse gênero. Observou-se, ao longo das análises, que, especificamente, os modalizadores deônticos de obrigatoriedade e os deônticos volitivos, não apenas em função da quantidade de ocorrências, mas, sobretudo, em função do papel que eles exercem no próprio texto, constituem-se parte integrante do funcionamento semânticoargumentativo dos contratos e, por esse motivo, são característicos do estilo linguístico desse gênero.
\end{abstract}

PALAVRAS-CHAVE: Argumentação, Modalização, Gênero Contrato.

\begin{abstract}
The main purpose of this research is to analyze and describe the semantic-argumentative operation of deontics modalizers in genre Contract, whose purpose is to establish an agreement between persons transferring, to one another, certain rights or are subject to obligations. The theory that our work embrace is based on studies of Modalization Discourse, presented by Lyons (1977), Cervoni (1989), Koch (2009), Castilho and Castilho (1993), Neves (2010), Nascimento and Silva (2012) among others, as well as the theory of genres proposed by Bakhtin (2000 [1979]). In addition to this contribution, this work is also based on Argumentation theory of Language proposed by Ducrot and collaborators (1988). Our corpus is composed by ten (10) contracts that were collected in public and private institutions, as well as world wide web. This research has a qualitative,
\end{abstract}

\footnotetext{
1 Professora efetiva do curso de Secretariado Executivo Bilíngue da Universidade Federal da Paraíba (UFPB) - Campus IV - Litoral Norte. Mestra em Linguística pelo Programa de Pós-Graduação em Linguística (PROLING) da Universidade Federal da Paraíba (UFPB).E-mail: katiargd83@gmail.com

2 Professor associado da Universidade Federal da Paraíba (UFPB), vinculado ao Programa de Pós-Graduação em Linguística e ao Programa de Mestrado Profissional em Letras (PROFLETRAS/UFPB). Doutor em Letras pela Universidade Federal da Paraíba (2005). Realizou Estágio de Pós-Doutorado na Universidad de Buenos Aires Argentina. Atualmente é Vice-Diretor do CCAE (Centro de Cienecias Sociais Aplicadas) da Universidade Federal da Paraíba - UFPB. E-mail: erypn@hotmail.com
} 
descriptive and an interpretive nature, as we describe the semantic-argumentative operation of deontics modalizers and meaning effects caused by its use in the objects of research texts. The theory the we have adopted allowed us to understand how these modalizers work strategically in this genre. We observed, over the analysis, that, especially, the deontic modals of obligation and volitional deontic, not only because of the number of occurrences, but mainly due to the role they play in the text itself, constitutes an integral part of the very structure of the contracts and, therefore, are characteristic of the linguistic style of this genre.

KEYWORDS: Argumentation, Modalization, Contract Genre.

\section{INTRODUÇÃO}

Cotidianamente os indivíduos se comunicam verbalmente por meio de gêneros, sejam eles orais ou escritos, nos mais diferentes campos da atividade humana, como bem afirmou Bakhtin (2000 [1979]). Na esfera jurídica, por exemplo, o Contrato se apresenta como um tipo de gênero por meio do qual é firmado um acordo entre partes interessadas, sob determinadas condições. Segundo Beltrão e Beltrão (2005), o contrato é uma espécie de documento pelo qual se estabelece convenção ou acordo entre pessoas e entidades, em que estas se obrigam uma com a outra a dar, fazer ou não fazer alguma coisa.

Embora pertencente à esfera jurídica, visto que esta é responsável por criar e estabelecer as normas e leis que regem os acordos instituídos, bem como garantir a execução e o cumprimento dos contratos, esse gênero é utilizado com bastante frequência, principalmente, pela administração pública e por entidades privadas, para firmar os mais diversos tipos de ajustes.

Com isso, para redigir um contrato, os profissionais que têm como ferramenta de trabalho a produção escrita desse tipo de gênero, geralmente, recorrem aos manuais de redação oficial e, principalmente, a literaturas voltadas para a realização do direito civil e administrativo.

Esses manuais orientam quanto ao uso de normas em relação à organização estrutural e de formatação dos elementos textuais. Informam sobre os tipos de contratos e em quais casos devem ser usados, composição de cláusulas, bem como apresentam questões relacionadas às diretrizes legais que orientam a produção, validação e cumprimento desses contratos. No entanto, apesar de essas orientações serem significativas para a construção estrutural do texto, não são suficientes, uma vez que não expõem aspectos relacionados ao uso da língua, ao modo como ocorre o processo de interação com interlocutores e os direcionamentos que o locutor pode dar ao texto com o intuito de alcançar objetivos esperados.

Um possível aspecto discutível desses manuais, ainda no que se refere ao tratamento dado à forma, é com relação à maneira de realização da redação dos contratos, visto que é comum haver prescrições de uso de uma linguagem neutra, clara, breve, simples e distante de marcas de pessoalidade. Haggar (1996), por exemplo, afirma que, para bem se elaborar um contrato, deve-se utilizar um "tom" de vOz adequado ao uso profissional, não deixando margens para impressões pessoais.

Entretanto, Marcuschi (2008) assegura que os gêneros, embora possuam uma entidade, que na produção textual nos condicionam a determinadas escolhas que não se apresentam de forma totalmente livre, principalmente, sob o ponto de vista do léxico, graus de formalidade ou natureza dos temas, ainda assim não devem ser concebidos como modelos estanques ou estruturas rígidas, pelo contrário precisam ser considerados como entidades dinâmicas, isto é, "como formas culturais e cognitivas de ação social corporificadas de modo particular na linguagem” (p. 156).

Com isso percebe-se que, embora seja de suma importância à adoção de procedimentos formais e normativos, exigidos em função do papel social que esse gênero assume nas situações reais de uso, não se pode negar que o processo de escrita é construído de forma dinâmica, visto que tais profissionais não se comunicam por acaso, mas porque se propõem a alcançar 
determinados objetivos, e é em função disso que eles agem de maneira criativa, produzindo enunciados significativos na busca por atender às necessidades das instituições a que pertencem ou que representam.

Assim, nesse processo, é inegável que o falante deixa registradas, em seu texto, marcas de sua subjetividade, que denunciam seus posicionamentos, avaliações ou pontos de vista, evidenciados por meio de estratégias e fenômenos argumentativos na interação com os interlocutores, as quais precisam ser consideradas.

Essas estratégias e esses fenômenos ficam registrados no próprio discurso e são revelados através de elementos linguísticos que provocam diferentes efeitos de sentido nos enunciados. Entre os elementos que imprimem argumentatividade na estrutura da língua e, consequentemente, nos diferentes gêneros discursivos, estão os modalizadores, objeto de nossa investigação.

Assim, esta investigação nos permitiu atentar para o modo como a argumentatividade se processa no gênero discursivo Contrato, especialmente pela presença dos modalizadores deônticos, contribuindo para uma melhor descrição das características semântico-discursivas do referido gênero e revelando aspectos que vão além dos abordados pelos manuais didáticos.

A fundamentação teórica adotada neste trabalho tem base nos estudos sobre a Modalização Discursiva, apresentada por Lyons (1977), Cervoni (1989), Koch (2009), Castilho e Castilho (1993), Neves (2010), Nascimento e Silva (2012), entre outros, bem como na teoria dos Gêneros Discursivos proposta por Bakhtin (2000 [1979]), e ainda se apoia na Teoria da Argumentação na Língua proposta por Ducrot e colaboradores (1988).

De modo geral, essa investigação tem como objetivo analisar e descrever a ocorrência e o funcionamento semântico-discursivo dos modalizadores deônticos (os quais se subdividem em deônticos de obrigatoriedade, possibilidade, proibição e volitivo), no gênero discursivo Contrato, como estratégia semântico-argumentativa, que permite ao locutor responsável pelo discurso expressar avaliações e atitudes perante o dito, e ainda identificar os efeitos de sentido que esses modalizadores geram nos contratos em que aparecem.

Vale destacar que essa classificação dos modalizadores deônticos tem base na categorização proposta por Nascimento e Silva (2012), visto que essa adequa-se aos objetivos desta pesquisa, bem como atende aos fenômenos apresentados no corpus investigado.

Especificamente, ainda objetivamos analisar quais os efeitos de sentido gerados pelo uso de tais modalizadores na construção dos argumentos utilizados na escrita do gênero; identificar se os modalizadores deônticos se constituem em característica semântico-discursiva e, consequentemente, do próprio estilo linguístico do gênero Contrato.

A presente pesquisa é de natureza quali-quantitativa, de cunho descritivo e interpretativista, uma vez que descrevemos o funcionamento semântico-argumentativo dos modalizadores e os efeitos de sentido provocados por sua utilização nos textos objetos de investigação.

O corpus da pesquisa é composto por 10 (dez) contratos coletados em instituições públicas e privadas, além da rede mundial de computadores. Esses contratos foram divididos da seguinte maneira: dos dez contratos selecionados, cinco são contratos de prestação de serviço e a outra metade, são contratos de locação. Após a coleta do corpus, realizamos uma análise nos contratos selecionados, a fim de identificar as ocorrências dos modalizadores presentes nos textos.

\section{Modalização e modalidade: conceitos e tipologias}

Falar de modalização implica, conforme expõe Neves (2010), tratar de conceitos advindos da Lógica, como "possibilidade" e "necessidade". A autora chama a atenção para o fato de que, tradicionalmente, essas noções estão na base da subtipologização das modalidades. Nesse sentido, todos os tipos de modalidade partem dos estudos desses dois operadores modais.

Segundo Cervoni (1989), o conceito de modalidade pertence tanto aos lógicos quanto aos linguistas, no entanto, os lógicos foram os primeiros a elaborá-lo, e este permanece um de seus 
conceitos fundamentais. Para o referido autor, a conceituação mais geral a que frequentemente se recorre para tratar de modalidade é a seguinte: a ideia de que uma análise semântica permite distinguir, em um enunciado, um dito, que é o conteúdo proposicional, de uma modalidade, tida como o ponto de vista do falante sobre esse dito. No entanto, para o referido autor, essa conceituação "não passa de uma aparência de definição que suscita todo tipo de explicitações, de complementos, até de retoques" (CERVONI, 1989, p. 53).

Segundo o autor, as definições que se propõem a realizar esse tipo de distinção, não especificam o que se entende por modalidade, em função de serem muito abrangentes. Por esse motivo, a proposta apresentada por Cervoni (1989) tem como finalidade delimitar o que se compreende como modalidade, e se propõe a diferenciar aquilo que ele considerou como "tipicamente modal", do que seja "parcialmente modal", e inclusive o que se convencionou excluir do campo das modalidades.

Nesse sentido, na classificação sugerida pelo referido autor, o que é identificado como tipicamente modal, é determinado como "núcleo duro", o qual é constituído por tudo aquilo que compreende de modo característico as noções de modalidade alética, epistêmica e deôntica. Este é constituído pelas modalidades proposicionais e pelos auxiliares de modo, pelo fato de poderem ser colocados no mesmo plano, uma vez que ambos "têm uma significação essencialmente modal perfeitamente explícita” (CERVONI, 1989, p. 63).

Em contraste a essa visão, Koch $(2009$, p. 73), ao tratar sobre as modalidades, assume o ponto de vista pragmático, em que, deixando "de examinar as hipóteses puramente sintáticas e/ou semânticas", passa a considerá-las como "parte da atividade ilocucionária do falante", por conceber as modalidades como uma revelação da "atitude do falante perante o enunciado que produz". Segundo a autora, "na estruturação de um discurso, a relação entre enunciados é frequentemente projetada a partir de certas relações de modalidade" (KOCH, 2009, p. 72), que se materializam por meios dos diversos modos de lexicalização que a língua dispõe (os operadores modais).

Koch $(2009$, p. 83) ainda assegura que compreender as modalidades crer e saber como um pressuposto geral a todas as outras modalidades, e ainda aceitar a possibilidade de sua ocultação, consolida a posição de que "não existem enunciados neutros". Ou seja, enunciados não modalizados, sem modalização, e essa afirmação da autora é baseada na tese de Ducrot e Anscombre (1976) de que a argumentatividade se constitui como uma característica imanente da linguagem humana.

Outra autora que também discute a possibilidade de existência ou não de modalidade em enunciados que não apresentam marcas notáveis ou explícitas de modalização é Neves (2010). Para esta autora, se modalizar implica um conjunto de relações entre locutor, enunciado e realidade objetiva, seria conveniente propor que não existem enunciados não-modalizados. Contudo, a autora deixa claro que esse não é um ponto de vista comum, essa discussão diverge bastante entre os estudiosos da temática.

Segundo Neves (2010), do ponto de vista comunicativo-pragmático, a modalidade é considerada como uma categoria automática, isso porque não seria admissível que o falante não marcasse de alguma forma seus enunciados, imprimindo neles certo grau de certeza sobre o fato expresso.

Nascimento (2010), que também compartilha da concepção pragmática adotada por Koch (2009) sobre as modalidades, postula que a modalização se constitui em um fenômeno que possibilita ao locutor deixar marcas de sua subjetividade e imprime o modo como o discurso deve ser compreendido. Segundo o referido autor, a modalização pode recair sobre o enunciado como um todo, sobre parte deste, ou ainda sobre todo o texto, ou discurso, e pode ainda incidir sobre o enunciado de outros locutores ou do interlocutor. Ou seja, a modalização ultrapassa os limites do enunciado e, nesse sentido, o autor se opõe à abordagem de alguns autores, tais como Cervoni (1989), que concebem a modalização apenas dentro dos limites do enunciado. 
Diante dessas considerações, percebe-se que esse ponto de vista semântico-pragmático adotado por Koch (2009), Neves (2010) e Nascimento (2010), com relação ao fenômeno da modalização, é totalmente oposto ao de uma concepção restrita adotada por outros estudiosos, a exemplo de Cervoni. Na perspectiva semântico-pragmática, o fenômeno da modalidade ou modalização vai além das fronteiras do enunciado ou da proposição, estendendo-se pelos aspectos contextuais, em que se consideram as atitudes e intenções do falante, incluindo seus objetivos e a forma como este deseja interagir com seus interlocutores, o que inclui as orientações argumentativas dos enunciados e do discurso.

Por concordarmos com esses estudiosos, destacamos que nossas análises serão baseadas no ponto de vista semântico-pragmático e, assim como tais estudiosos, conceberemos a modalização como sendo uma estratégia semântico-argumentativa e pragmática, que permite ao locutor imprimir diversos efeitos de sentido em seu discurso, tais como: estabelecer uma ordem ou asserção, dar permissão ou proibição, gerar incertezas, entre outros. Através desse fenômeno, é possível identificar as marcas deixadas pelo locutor de suas intenções, julgamentos, desejos etc. Com isso, há uma atitude do falante em relação ao dito, e esta é feita com base em seus objetivos e em função de seu interlocutor, isto é, visando de alguma forma influenciá-lo.

Em se tratando da tipologia das modalizações, não muito diferente do que ocorre em relação à conceituação da modalização, no que se refere à definição de suas tipologias, também é possível observar algumas divergências com relação às denominações adotadas e ao ponto de vista apresentado pelos estudiosos sobre a temática.

Assim, neste trabalho, adotaremos a classificação dos elementos modalizadores propostos por Nascimento e Silva (2012), visto que essa classificação adequa-se aos objetivos desta pesquisa, bem como atende aos fenômenos apresentados no corpus investigado.

A categorização apresentada pelos autores é fundamentada inicialmente na proposta de Castilho e Castilho (1993) e posteriormente é reformulada com a finalidade de abranger as ocorrências do fenômeno da modalização constatadas nas investigações realizadas pelo projeto ESAGD (Estudos Semânticos Argumentativos de Gêneros do Discurso: Redação Escolar e Gêneros Formulaicos).

Nascimento e Silva (2012) afirmam que os modalizadores são classificados com base no tipo de modalização que expressam nos enunciados e discursos em que aparecem. Esses estudiosos agrupam esses elementos em quatro grandes grupos: Modalização epistêmica; Modalização deôntica; Modalização avaliativa; e Modalização delimitadora.

Na sequência, expomos o quadro apresentado por Nascimento e Silva (2012), que contém a sintetização dos quatro tipos de modalização, bem como os seus subtipos.

Quadro 1: Tipos e subtipos de modalização

\begin{tabular}{|l|l|l|}
\hline Tipos de Modalização & \multicolumn{1}{|c|}{$\begin{array}{c}\text { Subtipos de } \\
\text { Modalização }\end{array}$} & \multicolumn{1}{|c|}{ Efeito de sentido no enunciado ou enunciação } \\
\hline $\begin{array}{l}\text { Epistêmica - expressa avaliação } \\
\text { sobre o caráter de verdade ou } \\
\text { conhecimento }\end{array}$ & Asseverativa & Apresenta o conteúdo como algo certo ou verdadeiro. \\
\cline { 2 - 3 } & Quase-asseverativa & $\begin{array}{l}\text { Apresenta o conteúdo como algo quase certo ou } \\
\text { verdadeiro. }\end{array}$ \\
\cline { 2 - 3 } & Habilitativa & $\begin{array}{l}\text { Expressa a capacidade de algo ou alguém realizar o } \\
\text { conteúdo do enunciado. }\end{array}$ \\
\hline $\begin{array}{l}\text { Deôntica - expressa avaliação } \\
\text { sobre o caráter facultativo, } \\
\text { proibitivo, volitivo ou de } \\
\text { obrigatoriedade }\end{array}$ & De obrigatoriedade & $\begin{array}{l}\text { Apresenta o conteúdo como algo obrigatório e que } \\
\text { precisa acontecer. }\end{array}$ \\
\cline { 2 - 3 } & De proibição & $\begin{array}{l}\text { Expressa o conteúdo como algo proibido, que não pode } \\
\text { acontecer. }\end{array}$ \\
\cline { 2 - 3 } & De possibilidade & $\begin{array}{l}\text { Expressa o conteúdo como algo facultativo ou dá } \\
\text { permissão para que algo ocorra. }\end{array}$ \\
\cline { 2 - 3 } & Volitiva & \begin{tabular}{l} 
Expressa um desejo ou vontade de que algo ocorra. \\
\hline
\end{tabular}
\end{tabular}




\begin{tabular}{|l|l|l|}
\hline $\begin{array}{l}\text { Avaliativa - expressa avaliação ou } \\
\text { ponto de vista }\end{array}$ & $\begin{array}{l}\text { Expressa uma avaliação ou ponto de vista sobre o } \\
\text { conteúdo, excetuando-se qualquer caráter deôntico ou } \\
\text { epistêmico. }\end{array}$ \\
\hline Delimitadora & $\begin{array}{l}\text { Determina os limites sobre os quais se deve considerar } \\
\text { o conteúdo do enunciado. }\end{array}$ \\
\hline
\end{tabular}

Fonte: NASCIMENTO; SILVA, 2012, p. 93 (Adaptado).

Vale salientar que em função dos objetivos deste trabalho, para realização das análises dos dados, focaremos apenas nos modalizadores deônticos. Em função disso, os demais modalizadores não serão investigados. Assim, na sequência, nos deteremos a expor mais detalhadamente apenas os modalizadores deônticos, os demais não serão apresentados, em razão do recorte feito para os fins deste trabalho.

A modalização deôntica refere-se aquela em que o locutor considera o conteúdo do enunciado como algo obrigatório ou necessário, facultativo ou permitido, proibido, ou expressão de um desejo. Nascimento e Silva (2012) chamam a atenção para o fato de Cervoni (1989) dividir essa modalidade em quatro eixos: o obrigatório, o proibido, o permitido e o facultativo, mas destacam que o referido autor não se preocupa em diferenciá-los, nem em exemplificá-los.

Com isso, Nascimento e Silva (2012) afirmam que a modalização deôntica vai além da "simples obrigatoriedade" e, partindo dessa posição, revelam que essa modalidade, além de expressar obrigatoriedade, também imprime permissão, proibição ou desejo, e, em função disso, subdividem-na em quatro tipos: deôntica de obrigatoriedade, deôntica de possibilidade, deôntica de proibição e deôntica volitiva.

A modalização deôntica de obrigatoriedade é aquela que revela que o conteúdo do enunciado deve ocorrer obrigatoriamente, gerando, assim, uma obrigação ao interlocutor, no sentido de que este deve obedecer a esse conteúdo. Já a modalização deôntica de possibilidade apresenta o conteúdo da proposição como algo facultativo e dá uma permissão para que o interlocutor exerça-o ou adote-o.

Quanto ao terceiro tipo, a deôntica de proibição, indica que o conteúdo da proposição é algo proibido e deve ser tido como tal pelo provável interlocutor. Enquanto que o último tipo de modalização deôntica, a volitiva, é aquela que expressa um desejo ou vontade, que parte do locutor. Nascimento e Silva (2012, p. 86) destacam que esse modalizador "pode funcionar como uma estratégia argumentativo-pragmática através da qual um locutor pode pedir ou solicitar a seu interlocutor que realize algo que deseja".

\section{$3 \mathrm{O}$ contrato como um gênero discursivo}

De acordo com Bakhtin (2000 [1979]), todos os diferentes campos da atividade humana se relacionam através da utilização da língua, e é em função da diversidade desses campos que se compreende como o caráter e os modos de uso da língua podem ocorrer de formas tão variadas.

Para Bakhtin (2010), o emprego da língua é realizado por meio de enunciados (textos) que são proferidos pelos participantes das inúmeras situações comunicativas. Esses enunciados referem-se a "real unidade da comunicação discursiva" (2010, p. 274), através dos quais os falantes, sujeitos da enunciação, elaboram seus discursos.

Nesse sentido, os gêneros discursivos são conceituados por Bakhtin (2000 [1979]) como sendo tipos de enunciados relativamente estáveis, que provêm das diversas esferas da atividade humana. Essa estabilidade, de acordo com autor, deve ser interpretada do ponto de vista "temático, composicional e estilístico" (2000 [1979], p. 284), pois cada gênero se apresenta, com relação a esses três aspectos, de uma maneira consolidada e é por esse motivo que cada domínio social é capaz de reconhecer seus gêneros e utilizá-los para fins distintos.

Bakhtin (2000 [1979]) além de considerar em que circunstâncias e com que intenções os gêneros são produzidos, ainda estabelece três critérios que precisam ser observados para que se possa identificar um gênero: o conteúdo temático, o estilo e a construção composicional. 
O conteúdo temático está relacionado ao tipo de assunto que é veiculado nos gêneros, ou seja, refere-se às informações tratadas. Já o estilo, segundo Bakhtin (2000 [1979]), está relacionado aos recursos da língua, tais como os recursos lexicais, fraseológicos e gramaticais com que cada gênero é composto. Por fim, à construção composicional está relacionada com a forma ou estrutura de um determinado gênero textual. Como aponta Bakhtin (2000 [1979], pág. 301): "todos os nossos enunciados dispõem de uma forma padrão e relativamente estáveis de estruturação de um todo".

Ao se considerarem esses critérios estabelecidos por Bakhtin (2000 [1979]) para que se possa identificar um gênero pode-se melhor definir o gênero Contrato e observar suas peculiaridades de maneira mais precisa. Desse modo, conceitualmente, sabe-se que o Contrato é tipo de gênero utilizado, de acordo com Medeiros (2006), para estabelecer um acordo entre duas ou mais pessoas, que transferem uma para a outra, determinados direitos ou se sujeitam a obrigações.

Para Meirelles (1990), o contrato é definido como sendo um tipo de acordo de vontades que gera obrigações e direitos para as partes envolvidas. Para o referido autor, "em princípio, todo contrato é negócio jurídico bilateral e comutativo, isto é, realizado entre pessoas que se obrigam a prestações mútuas e equivalentes em encargos e vantagens" (1990, p. 211). Nesse sentido, por se tratar de um pacto consensual, pressupõe-se que as partes sejam livres e capazes para se obrigarem validamente, e, devido ao caráter jurídico, é necessário que o objeto contratual seja lícito, que se apresente de maneira prescrita e não vedada em lei.

No que se refere ao conteúdo temático, percebe-se que o contrato pode tratar de assuntos diversos; isso vai depender da finalidade a que se propõe o texto, pois são vários os tipos de contratos e cada um deles apresenta objetivos diferentes. Assim, alguns dos mais utilizados são: contrato de concessão, contrato de gerenciamento, contrato de fornecimento, prestação de serviços e os de locação. Vale destacar que esses últimos (prestação de serviços e os de locação), constituemse objetos de estudo dessa investigação.

Quanto ao estilo, dependendo da esfera social na qual esse gênero é veiculado e do tipo de assunto tratado, este pode também variar bastante. Desse modo, os contratos produzidos pelo meio jurídico, em função do caráter normativo dessa esfera, apresentam alto grau de formalidade, vocabulário mais rebuscado e utilização de expressões específicas desse domínio discursivo.

Segundo Galdino (2014), a área do direito é conhecida tanto pelos seus gêneros particulares (tais como: contrato, petição, intimação, parecer, entre outros) como por sua linguagem complexa ${ }^{3}$. Assim, entende-se que as formas linguísticas ou funcionais presentes no contrato refletem as peculiaridades dessa esfera discursiva e são características desse tipo de gênero.

Quanto à construção composicional, Gasparini (2007) destaca que o contrato administrativo é composto por três partes: preâmbulo, texto e encerramento. O preâmbulo refere-se à parte superior do contrato, onde são mencionados os nomes dos contratantes.

O texto é a parte que vem na metade do contrato, na qual devem constar as cláusulas que expressam com precisão a vontade dos contratantes no momento da celebração do contrato e que consolida o conteúdo do acordo. Desse modo, as cláusulas devem "descrever o objeto do ajuste, estabelecer as condições de sua execução e definir os direitos, obrigações e responsabilidades dos contratantes, observados os termos da licitação, isto é, do edital e da proposta" (GASPARINI, 2007, p. 668).

O último ponto, o encerramento, como o próprio nome já indica, refere-se à parte final do contrato. Nessa parte consta o fecho, através do qual os envolvidos declaram que, "por estarem do acordo com o pactuado, o assinam em tantas vias de igual teor e forma, para os mesmos efeitos e

\footnotetext{
${ }^{3}$ Linguagem complexa para Galdino (2014) está relacionada ao excesso de arcaísmos, latinismos e de vocabulário rebuscado que propiciaram a denominação da linguagem jurídica como inacessível e de difícil entendimento.
} 
direitos, e, depois da consignação do local e data, apõem as suas respectivas assinaturas" (GASPARINI, 2007, p. 670).

Após termos identificado o gênero Contrato, que se constitui em nosso corpus de pesquisa, nas próximas seção, além dos procedimentos metodológicos utilizados nesta investigação, apresentaremos ainda as análises que foram realizadas nos contratos investigados, com o propósito de expor como se dá a ocorrência dos modalizadores nesse gênero do discurso e, ainda, mostrarmos quais os efeitos de sentido que a presença de tais modalizadores gera no Contrato.

\section{PROCEDIMENTOS METODOLÓGICOS}

A presente investigação é de natureza quali-quantitativa, de cunho descritivo e interpretativista, realizada através da análise de dados documentais. Segundo Godoy (1995), a abordagem qualitativa oferece três possibilidades de se realizar, e uma delas é por meio da pesquisa documental. Para o referido autor, esse tipo de pesquisa refere-se àquele em que o exame de materiais, de natureza diversa, ainda não sofreu nenhum tratamento analítico e tem como finalidade buscar novas interpretações complementares.

Conforme já mencionado na introdução, essa investigação tem como objetivo analisar e descrever a ocorrência e o funcionamento semântico-discursivo dos modalizadores deônticos (os quais se subdividem em deônticos de obrigatoriedade, possibilidade, permissão e desejo) no gênero discursivo Contrato, como estratégia semântico-argumentativa, que permite ao locutor responsável pelo discurso expressar avaliações e atitudes perante o dito, e ainda identificar os efeitos de sentido que esses modalizadores geram nos contratos em que aparecem.

Assim, nesta pesquisa, partimos da observação do corpus selecionado, para descrevermos o funcionamento semântico-argumentativo dos modalizadores deônticos e os efeitos de sentido provocados por sua utilização nos textos objetos de investigação. Ao término das análises resolvemos quantificar as ocorrências dos modalizadores, a fim de evidenciar melhor os resultados obtidos.

O corpus da investigação foi composto por 10 (dez) contratos coletados em instituições públicas e privadas, além da rede mundial de computadores. Optamos por dividir o corpus da seguinte maneira: dos dez contratos selecionados, cinco são contratos de prestação de serviço e a outra metade são contratos de locação.

Assinalamos ainda que, para manter a privacidade das instituições e pessoas envolvidas no processo de produção dos textos, esses contratos serão identificados por números, obedecendo a uma sequência que vai do 01 ao 05 para os contratos de prestação, de serviço, e do 06 ao 10 para os contratos de locação.

Quanto aos nomes e dados particulares das pessoas e instituições citadas nos textos, estes serão substituídos pela letra "X". Cada tipo de contrato será mencionado por uma sigla, conforme se observa no quadro seguinte.

Quadro 02 - Identificação dos Contratos

\begin{tabular}{|c|c|}
\hline Tipo de contrato & Identificação \\
\hline Contrato de Prestação de Serviço & Contrato PS \\
\hline Contrato de Locação & Contrato L \\
\hline
\end{tabular}

Fonte: elaboração própria

Quanto à transcrição dos enunciados, destacamos que estes foram registrados mantendo o texto original, isto é, não realizamos qualquer alteração quanto à correção gramatical, de desvios ortográficos, digitação e grifos do autor responsável pelos textos. No entanto, a grafia foi adaptada com a fonte Times New Roman, tamanho 12 e espaçamento simples, visando manter a padronização do presente trabalho. 
Para demonstrar a ocorrência dos modalizadores deônticos, no interior de cada trecho, assinalamos a presença dos modalizadores detectados nos contratos analisados de acordo com os seus tipos e cores, conforme o quadro que segue.

Quadro 03 - Tipos de modalizadores deônticos - indicação por cores

\begin{tabular}{|l|l|}
\hline Modalizador Deôntico de Obrigatoriedade \\
\hline & Modalizador Deôntico de Possibilidade \\
\hline & Modalizador Deôntico de Proibição \\
\hline & Modalizador Deôntico Volitivo \\
\hline
\end{tabular}

Fonte: elaboração própria

\section{ANÁLISE DOS MODALIZADORES DEÔNTICOS NO GÊNERO CONTRATO}

$\mathrm{Na}$ sequência, apresentamos as análises que foram realizadas nos contratos de prestação de serviço e de locação, que compõem o nosso corpus. Salientamos que os contratos foram analisados em sua totalidade, porém, para demonstrar a ocorrência de cada tipo de modalização recorrente nesse gênero, destacamos apenas alguns trechos, que estão elencados abaixo.

\subsection{Modalização Deôntica}

A modalização deôntica é aquela que, além de expressar obrigatoriedade e possibilidade, também revela permissão e proibição. Seus subtipos estão relacionados abaixo.

\subsubsection{Modalização deôntica de obrigatoriedade}

Esses modalizadores são aqueles que geram uma obrigatoriedade ao interlocutor, não lhe deixando outra opção senão a de obediência. Em nosso corpus, tais modalizadores atuam de maneira coerente, revelando como o locutor orienta seus interlocutores, no sentido de indicar como estes devem agir diante do que está sendo dito, conforme se observa nos trechos em destaque.

\begin{tabular}{|c|c|c|}
\hline \multicolumn{3}{|c|}{ Quadro 04 - Ocorrência da Modalização Deôntica de Obrigatoriedade } \\
\hline Trecho & Contrato & Modalização Deôntica de Obrigatoriedade \\
\hline Trecho 01 & Contrato PS - n 01 & $\begin{array}{l}\text { A cada seis meses, até a integralização do Curso, o } \\
\text { CONTRATANTE deverá fazer a Matrícula Semestral e as partes } \\
\text { assinarão novo termo contratual de prestação de serviços } \\
\text { educacionais, de acordo com a Lei } 9.870 / 99 \text { e com as normas da } \\
\text { XXXXXXX/XXX. }\end{array}$ \\
\hline Trecho 02 & Contrato PS - n 04 & $\begin{array}{l}{[\ldots] \text { As partes se obrigam a cumprir o presente contrato fielmente, }} \\
\text { por si e por seus sucessores a qualquer título. }\end{array}$ \\
\hline Trecho 03 & Contrato PS - n 04 & $\begin{array}{l}2.5 \text { - A CONTRATADA orienta o uso dos seguintes } \\
\text { procedimentos por parte do Cliente: abrir uma conta bancária em } \\
\text { nome da pessoa jurídica; fazer cópia de todos os cheques utilizados } \\
\text { em nome da empresa; não utilizar o caixa ou cheques da empresa } \\
\text { para pagamento alheios à mesma; efetuar preenchimento diário do } \\
\text { livro boletim de caixa ou algo que o substitua; emitir notas fiscais } \\
\text { para toda e qualquer venda de produtos ou serviço, registrando as } \\
\text { respectivas entradas de numerário no livro boletim de caixa; não } \\
\text { deixar que se acumulem dúvidas quanto aos procedimentos relativos } \\
\text { ao desenvolvimento da sua empresa; comunicar (imediatamente) a } \\
\text { CONTRATADA ao receber visitas de fiscais; pedir (sem } \\
\text { constrangimentos) a identificação de toda pessoa que surgir no seu } \\
\text { estabelecimento comercial sob o pretexto de fiscalização [...]. }\end{array}$ \\
\hline
\end{tabular}

Fonte: elaboração própria 
No trecho 01 do contrato de prestação de serviço $n^{\circ}$ 01, percebe-se que é expressa uma noção de obrigatoriedade, no momento em que se faz uso do verbo "deverá". Essa obrigatoriedade é no sentido de instruir ou indicar como o locutor contratante (que nesse caso refere-se ao aluno da instituição) deve agir. Isto é, a cada seis meses, até que o curso seja concluído, esse aluno deverá necessariamente efetuar a matrícula semestral e assinar um novo contrato. Com isso, é possível perceber que o efeito de sentido que se gera no enunciado é de que tal instrução precisa ser cumprida obrigatoriamente. Desse modo, não resta outra leitura a não ser exatamente a de obediência.

No trecho seguinte, observa-se que a expressão da obrigatoriedade recai sobre os dois locutores responsáveis pelo texto do contrato de prestação de serviço (estes denominados contratante e contratada). Ao fazer uso do modalizador "se obrigam", tais locutores se comprometem a cumprir de maneira fiel o ajuste a que faz referência o contrato. É interessante destacar que, neste caso, o modalizador deôntico de obrigatoriedade atua com forte caráter asseverativo, pois, conforme se percebe, nessa marca de modalidade fica implícito o conhecimento de ambas as partes sobre o conteúdo do enunciado, ou seja, do compromisso assumido, e isso se apresenta como algo certo (além de obrigatório, é certo que elas se obrigam), logo verdadeiro.

$\mathrm{Na}$ sequência, no trecho 03 do contrato de prestação de serviço $\mathrm{n}^{\circ} 04$, verifica-se que é utilizada uma série de modalizadores sob a forma de verbos no infinitivo, tais como "fazer" "efetuar" e "comunicar". Esses verbos adquirem um caráter instrucional e, por isso, funcionam como modalizadores deônticos de obrigatoriedade, de maneira implícita: (Você deve ou tem que) "abrir uma conta bancária em nome da pessoa jurídica;" (Você deve ou tem que) "fazer cópia de todos os cheques utilizados em nome da empresa;" [...]" etc. Tais modalizadores dão instruções sobre o modo como a contratante deve proceder na execução dos serviços contábeis para com os seus clientes. É importante destacar, que os verbos no infinitivo, nesse tipo de gênero, especificamente, ganham a característica de modalizador deôntico de obrigatoriedade, uma vez que são usados para instruir.

Esse efeito de sentido também foi observado por Stutterheim (1993), em seu trabalho intitulado Modality: Function and Form in Discourse, em que destaca que, ao dar instruções, o falante pode, dentre outros modos, escolher apresentar todos os passos em construções de infinitivo, dessa maneira, a categoria modal deôntica ocorre implicitamente dentro de todo o texto, conforme se verifica no exemplo retirado do corpus da referida autora: Then to fix the red pieces - [Then (you have) to fix the red pieces] $]^{4}$ (pág. 18).

Do mesmo modo, o verbo "orienta", também destacado no trecho 03, se constitui em um modalizador deôntico de obrigatoriedade, o que pode decorrer da própria natureza instrucional do gênero contrato. No enunciado em que aparece, o referido verbo ganha um efeito de sentido de instrução, confirmando a noção de obrigatoriedade expressa pelos verbos no infinitivo. Além do verbo orientar, com efeito instrucional, é necessário observar o uso do termo "procedimentos", no mesmo enunciado, o que indica que tais orientações devem ser cumpridas. Através do uso desses elementos linguísticos, o locutor, além de especificar o modo como o locutor contratado precisa agir, também não lhe deixa outra alternativa a não ser seguir os procedimentos, visto que eles se constituem necessários para a execução dos serviços prestados pela contratada.

\subsubsection{Modalização deôntica de possibilidade}

Ocorre quando o conteúdo do enunciado é apresentado como algo facultativo, isto é, quando o falante permite que o interlocutor o exerça ou adote-o. Os trechos selecionados mostram como o locutor responsável pelo enunciado adota esse tipo de estratégia para facultar ou dar permissão para que o conteúdo do enunciado ocorra.

\footnotetext{
${ }^{4}$ Em seguida, para fixar as peças vermelhas - [Em seguida (você tem) para fixar as peças vermelhas]. (Tradução nossa).
} 
Quadro 05 - Ocorrência da Modalização Deôntica de Possibilidade

\begin{tabular}{|l|l|l|}
\hline Trecho & Contrato & Modalização Deôntica de Possibilidade \\
\hline Trecho 04 & Contrato PS - n ${ }^{\circ} 02$ & $\begin{array}{l}\text { O presente contrato vigorará por prazo indeterminado, podendo } \\
\text { qualquer das partes notificar a outra, com antecedência de 30 (trinta) } \\
\text { dias, para a rescisão do presente instrumento. }\end{array}$ \\
\hline Trecho 05 & Contrato L - no 06 & $\begin{array}{l}\text { Fica o LOCADOR ou seu representante legal, desde já autorizado } \\
\text { a ocupar, independente de ação ou medida de emissão de posse, sem } \\
\text { qualquer formalidade, o imóvel caso venha a ser desocupado e/ou } \\
\text { abandonado pelo(a) LOCATÁRIO(A). }\end{array}$ \\
\hline Trecho 06 & Contrato L - no 07 & $\begin{array}{l}\text { Vindo a ser feita benfeitoria, faculta ao LOCADOR aceitá-la ou } \\
\text { não, restando ao LOCATÁRIO em caso do LOCADOR não } \\
\text { aceitá-la, modificar o imóvel da maneira que lhe foi entregue. }\end{array}$ \\
\hline
\end{tabular}

No trecho 04, percebe-se que o verbo "podendo" está modalizando o enunciado: "qualquer das partes notificar a outra, com antecedência de 30 (trinta) dias, para a rescisão do presente instrumento". A través do modalizador em destaque, é expressa uma permissão, no sentido de indicar que qualquer uma das partes envolvidas no contrato notifique a outra, caso queira rescindir o contrato, com antecedência mínima de 30 dias. Conforme se observa, nesse enunciado não se verifica uma noção de obrigatoriedade, mas sim uma permissão para que o conteúdo do enunciado ocorra. Em função disso, esse conteúdo é apresentado como uma possibilidade. Assim, os locutores responsáveis pelo dito têm a permissão para realizá-lo, e isso lhes é facultado, ou seja, eles podem efetivá-lo ou não, mas essa decisão fica a critério deles.

$\mathrm{Na}$ sequência, no trecho 05 , fica clara a permissão dada ao locutor locador por meio do modalizador "autorizado". A autorização indica que o locador tem permissão para ocupar o imóvel locado, sem necessitar de formalidades, caso este venha a ser desocupado ou abandonado pelo locatário. Apesar de existir o consentimento, a decisão de aceitá-la ou não dependerá exclusivamente desse locutor.

No trecho 06, percebe-se que o conteúdo do enunciado é modalizado através do verbo facultar sob a forma "faculta". O efeito de sentido que se gera através desse modalizador no enunciado é o de permissão. Essa permissão recai sobre o locutor locador, ou seja, isso indica que o locador tem permissão para aceitar o conteúdo do enunciado, ou seja, em caso de serem feitas benfeitorias no imóvel locado, este locador pode aceitá-las ou não. Nesse enunciado, a decisão do locutor locador de aceitar a permissão está explícita, reforçando ainda mais que depende unicamente dele a decisão de acatá-la.

\subsubsection{Modalização deôntica de proibição}

Os modalizadores deônticos de proibição são utilizados pelo locutor quando este deseja expressar uma proibição. Essa proibição revela ao interlocutor que o conteúdo da proposição deve ser entendido como algo que não deve acontecer ou ser feito. Nos enunciados dos contratos em destaque é possível perceber como o locutor faz uso desse tipo de estratégia e qual efeito de sentido é gerado no discurso.

\begin{tabular}{|l|l|l|}
\multicolumn{4}{|c|}{ Quadro 06 - Ocorrência da Modalização Deôntica de Proibição } \\
\hline Trecho & Contrato & Modalização Deôntica de Proibição \\
\hline Trecho 07 & Contrato PS - n ${ }^{\circ} 02$ & $\begin{array}{l}\text { Os direitos e obrigações por este instrumento ajustados não } \\
\text { poderão, a nenhum título, ser transferidos ou cedidos, ficando } \\
\text { facultado, unicamente à CONTRATADA, sob sua exclusiva e inteira } \\
\text { responsabilidade, a contratação de pessoas físicas ou jurídicas, } \\
\text { equipes autônomas, prepostos ou repassadores, treinados e } \\
\text { devidamente credenciados pela CONTRATADA, para a realização } \\
\text { do convencionado na cláusula primeira. }\end{array}$ \\
\hline
\end{tabular}




\begin{tabular}{|l|l|l|}
\hline Trecho 08 & Contrato $\mathrm{L}-\mathrm{n}^{\circ} 06$ & $\begin{array}{l}\text { Ficando, desde já, PROIBIDA a sublocação a terceiros, ceder, } \\
\text { emprestar, gratuitamente ou onerosamente, no todo ou em } \\
\text { parte, bem como o uso do mesmo para festas ou uso de bebida } \\
\text { alcoólicas, com som em alto volume ou algazarra, uma vez que } \\
\text { se trata de um imóvel anexado à outros, sob pena de multa } \\
\text { (com valor correspondente ao aluguel de um mês do } \\
\text { apartamento) e/ou rescisão do contrato, independente de } \\
\text { notificação judicial ou extrajudicial. }\end{array}$ \\
\hline Trecho 09 & $\begin{array}{l}\text { A presente locação destina-se exclusivamente a fins COMERCIAIS } \\
\text { PARA O RAMO DE COLCHÕES E AFINS da Locatária, } \\
\text { contrato L - no }{ }^{\circ} 09 \\
\text { sendo vedada a alteração desta finalidade sem a expressa } \\
\text { concordância do Locador por escrito. }\end{array}$ \\
\hline
\end{tabular}

Fonte: elaboração própria

No trecho 07 , observa-se que a modalização deôntica de proibição recai sobre todo o conteúdo do enunciado, sendo expressa através da expressão "não poderão", que está indicando a impossibilidade de transferência ou cessão dos direitos e obrigações estabelecidos no ajuste em questão a terceiros. Essa proibição, no entanto, não é dada exclusivamente a uma das partes envolvidas no acordo, mas as duas, isto é, tanto à contratante como à contratada.

No trecho 08 , do contrato de locação $n^{\circ} 06$, é apresentada uma proibição que é direcionada ao locutor locatário. A proibição é no sentido de impedi-lo de fazer uso do imóvel para realizar "sublocaşão a terceiros, ceder, emprestar, gratuitamente ou onerosamente, no todo ou em parte, bem como o uso do mesmo para festas ou uso de bebida alcoólicas, com som em alto volume ou algazarra". Como se observa, essa proibição é reforçada através do emprego de marcas textuais, tais como os destaques realizados em caixa alta na palavra "proibida" e do uso de negrito em todo o texto, bem como através da presença da penalidade imposta para o caso de descumprimento da proibição: "sob pena de multa (com valor correspondente ao aluguel de um mês do apartamento) e/ ou rescisão do contrato, independente de notificação judicial on extrajudicial'.

O outro trecho destacado, do contrato de locação $n^{\circ}$ 09, apresenta um caráter proibitivo que é marcado através da expressão "sendo vedada". Por meio dessa expressão, ocorre uma proibição que recai sobre o locutor locatário, a qual o impede de fazer uso do imóvel comercial para outros fins que não sejam os acordados no contrato, sem a expressa concordância do locador feita por escrito.

Conforme se observa, em todos os exemplos, esse modalizador também expressa uma obrigatoriedade. No entanto, esta não é pura, já que apresenta, além do sentido de obrigação, a noção de proibição, no sentido de se proibir que se realize algo, efeito de sentido próprio dos modalizadores deônticos de proibição, nos termos em que coloca Nascimento (2010).

\subsubsection{Modalização deôntica volitiva}

Ocorre quando o locutor expressa um desejo ou vontade. Essa modalização é utilizada como uma estratégia argumentativo-pragmática que possibilita ao locutor revelar seu pedido ou solicitar que o interlocutor o realize. Nos contratos, a exposição desse desejo revela uma vontade que é partilhada entre os locutores, conforme se percebe nos trechos em destaque.

Quadro 07 - Ocorrência da Modalização Deôntica Volitiva

\begin{tabular}{|l|l|l|}
\hline Trecho & Contrato & Modalização Deôntica Volitiva \\
\hline Trecho 10 & Contrato L - n ${ }^{\circ} 07$ & $\begin{array}{l}\text { As partes integrantes deste contrato ficam desde já acordadas a se } \\
\text { comunicarem somente por escrito, através de qualquer meio } \\
\text { admitido em Direito. }\end{array}$ \\
\hline Trecho 11 & Contrato PS - n ${ }^{\circ} 04$ & $\begin{array}{l}\text { Fica eleito o foro da Comarca de João Pessoa, do Estado da Paraíba, } \\
\text { para dirimir qualquer controvérsia oriunda do presente contrato. }\end{array}$ \\
\hline Trecho 12 & Contrato PS - n ${ }^{\circ} 01$ & $\begin{array}{l}{[. .] \text { doravante denominada simplesmente XXXXXXX e de outro }} \\
\text { lado, o (a) CONTRATANTE, identificado (a) acima e no Anexo I }\end{array}$ \\
\hline
\end{tabular}




\begin{tabular}{|l|l|l|}
\hline & $\begin{array}{l}\text { (Requerimento de Matrícula devidamente deferido), nos termos da } \\
\text { legislação civil em vigor, resolvem firmar o presente instrumento de } \\
\text { contratação de serviços educacionais para o semestre letivo de } \\
\text { 2015.1, que se regerá pelas cláusulas que se seguem. }\end{array}$ \\
\hline
\end{tabular}

No trecho 10 do contrato de locação residencial $n^{\circ} 07$, observa-se que o modalizador "ficam acordadas" está revelando um desejo ou vontade que é partilhado entre os locutores (que nesse caso, referem-se ao locador e locatário). Esse desejo está relacionado à necessidade de que todas as comunicações realizadas entre as partes sejam estabelecidas somente por escrito e através de qualquer meio admitido em Direito. Desse modo, é possível perceber que esse modalizador além de expressar uma vontade que faz com as partes concordem com o estabelecido, também imprime um forte caráter asseverativo, uma vez que este enunciado se apresenta com algo certo, ou seja, por ser objeto de um acordo, torna-se algo verdadeiro.

Semelhantemente, ao que ocorre no trecho anterior, também se verifica no enunciado do contrato $n^{\circ}$ 04, através da expressão "ficando eleito", mais uma ocorrência de modalização deôntica volitiva. Por meio dessa expressão, é possível observar que a escolha por esse foro, especificamente, "da Comarca de João Pessoa", foi realizada com base em uma vontade dos contratantes, isto é, em função do querer das partes envolvidas no acordo, escolheu-se esse foro e não outro. E, conforme se percebe, esse conteúdo também é apresentado como um valor de certeza, visto que toda a informação dada é tomada como algo verdadeiro. Assim, o modalizador "ficando eleito", além de expressar volição, também expressa asseveração.

Logo em seguida, no trecho 12, tem-se uma expressão bastante frequente nos contratos, "resolvem firmar". Essa expressão, geralmente, é utilizada na parte inicial do gênero com a finalidade de registrar que o acordo firmado, consolidado ou celebrado, é estabelecido por meio da livre vontade das partes. Nesse sentido, os locutores expressam que esse acordo é de total interesse e desejo de quem os celebra e, por esse motivo, consideramos o referido modalizador como deôntico volitivo, já que expressa o querer ou a vontade das partes. É importante observar que tal expressão também revela a noção de asseveração, visto que o conteúdo do enunciado é apresentado como uma certeza, que ratifica a realização do acordo. A noção de asseveração é marcada, principalmente, pelo verbo "resolvem", uma vez que esse verbo demonstra a certeza de que a decisão de fato ocorreu, ou seja, tais locutores resolveram firmar o acordo e isso foi feito.

Conforme se percebe, todos os modalizadores volitivos apontados nos trechos selecionados apresentam um forte valor asseverativo. No entanto, compreendemos que o caráter de vontade ou desejo se sobressai, em função da própria característica do gênero. Em função disso, consideramos estes modalizadores como deônticos de volição.

\section{CONSIDERAÇÕES FINAIS}

Nossa finalidade nesta investigação foi analisar e descrever a ocorrência e o funcionamento semântico-discursivo dos modalizadores deônticos no gênero discursivo Contrato, como estratégia semântico-argumentativa, que permite ao locutor responsável pelo discurso expressar avaliações e atitudes perante o dito, e ainda identificar os efeitos de sentido que esses modalizadores geram nos contratos em que aparecem.

Assim, em relação aos nossos objetivos podemos dizer que foram alcançados, pois os resultados de nossa investigação revelam e confirmam a presença e uso dos modalizadores deônticos, os quais se subdividem em quatro tipos: de obrigatoriedade, possibilidade, proibição e volitiva, no gênero examinado, como estratégia semântico-argumentativa, que permite ao locutor responsável pelo discurso, além de expressar posicionamentos e atitudes perante o dito, direcionar como o que está sendo dito deve ser lido. 
Os dados coletados mostraram que a modalização deôntica de obrigatoriedade apresentou o maior índice de ocorrências. Percebemos que, é por meio dos modalizadores deônticos de obrigatoriedade que os locutores, além de orientar a realização de ações das partes envolvidas no acordo, também transferem, uma para a outra, determinados deveres ou se sujeitam a certas obrigações.

Esses modalizadores revelaram um total de 185 ocorrências, sendo o tipo de modalização mais atuante em todos os contratos analisados. No entanto, esse resultado já era previsto. Como é próprio do gênero gerar direitos e obrigações para as partes envolvidas, o objetivo dos locutores ao fazer uso de tais modalizadores é, além de instruir os contratantes quanto à realização de ações, produzir um caráter de obrigatoriedade que expresse de maneira precisa, o que é de sua responsabilidade e, por isso, não pode deixar de ser cumprido.

No que se refere ao uso dos modalizadores deônticos volitivos, estes apresentaram um total de 23 ocorrências nos contratos analisados. Desse modo, percebemos que esses modalizadores, mesmo que não tenham apresentado uma ocorrência tão relevante como outros tipos de modalizadores (como os deônticos de obrigatoriedade, por exemplo), geram um efeito de sentido bastante peculiar no gênero Contrato. Os modalizadores volitivos, que são mais visíveis no início e no final do texto, atuam revelando a vontade dos locutores ou partes envolvidas no ajuste, no que se refere à realização do Contrato.

À vontade ou o querer dos contratantes é reforçada através dos deônticos volitivos, uma vez que estes modalizadores ratificam o acordo que se estabelece entre as partes contratantes, bem como deixam claro que esse acordo é de total interesse de quem os celebra. De certa forma, a presença de tais modalizadores atua sobre todo o texto dos contratos, uma vez que indicam que tudo que está expresso no conteúdo do texto é objeto de acordo e está relacionado com o querer e o interesse dos envolvidos. Acreditamos, com isso, que a utilização desses modalizadores nas partes iniciais e finais do gênero intensifica ainda mais a força argumentativa desses modalizadores, de forma estrategicamente situada.

Desse modo, por estar presente em todos os contratos analisados, embora não tenha sido a estratégia argumentativa que apresentou maior número de ocorrências, passamos a considerar que esse tipo de modalização, juntamente com os deônticos de obrigatoriedade, constitui-se parte da própria estrutura linguístico-discursiva dos contratos e, em função disso, são característicos desse tipo de gênero.

A realização dos deônticos de possibilidade se deu de forma significativa, sendo o terceiro tipo de maior ocorrência, totalizando 48 marcas, o que tem se mostrado um dado interessante. Mesmo diante do caráter acentuado de obrigatoriedade que esse tipo de gênero imprime, percebemos que os locutores fazem uso desses modalizadores para facultar que as partes envolvidas nos ajustes decidam, por conta própria, realizar ou não determinadas ações, embora, muitas vezes estas se mostrem com certas restrições. Esse tipo de atitude revela, em tais casos, uma atenuação do caráter de obrigatoriedade expresso pelo gênero.

Quanto aos deônticos de proibição, estes também demonstraram baixa ocorrência, apenas 16 casos. No entanto, esses modalizadores também revelam estratégias modalizadoras e argumentativas que foram utilizadas pelos locutores do gênero contrato, as quais já foram expostas nas análises.

Diante de tais constatações, podemos concluir, a respeito do gênero contrato, que a argumentatividade (a subjetividade e a intersubjetividade) se faz presente nesse tipo de texto, entre outras estratégias, pela presença dos modalizadores deônticos. Dessa forma, afirmamos que esses modalizadores são característicos do próprio estilo linguístico do gênero, já que se constituem em característica semântico-discursiva do contrato.

Esta investigação ainda nos permitiu refletir sobre o fato de que a linguagem utilizada pelos profissionais responsáveis discursivamente por esses textos não é neutra, ou isenta de marcas pessoais, pelo contrário, ela é rica em argumentatividade, que se pode materializar a través do uso 
de determinados elementos modalizadores, como foi comprovado nos resultados das análises do gênero investigado. Isso revela que, na produção escrita do gênero investigado, a subjetividade dos locutores vai sendo revelada através do uso dos modalizadores discursivos, o que permite revelar o direcionamento que estes mesmos locutores desejam dar ao próprio sentido dos enunciados, bem como evidenciam os posicionamentos assumidos frente ao conteúdo do dito.

Convém ressaltar que isso não ocorre à toa, mas em função das intenções ou objetivos que tais locutores pretendem atingir. No caso dos contratos, acreditamos que esses objetivos estejam bastante relacionados ao interesse de garantir que os envolvidos no acordo cumpram os direitos e obrigações estabelecidos. Por esse motivo, percebe-se que a presença dessas marcas não só faz parte do texto, mas contribui para o seu fortalecimento, uma vez que torna o texto mais significativo e, sobretudo, criativo.

Como é possível perceber, mesmo que exista uma padronização a ser seguida na elaboração de textos como o Contrato, que busca uma neutralidade, clareza, formalidade e objetividade, sempre haverá marcas da subjetividade do falante. A preocupação excessiva com a forma, por parte dos manuais de redação, conforme já dito anteriormente, mesmo que esta não possa ser negada, ou que possua a sua importância, é a prova de que o discurso de tais manuais não considera a língua como um lugar de interação, que envolve locutores/interlocutores, dotados de interesses e objetivos particulares. No entanto, mesmo com um alto padrão de formalidade e regulamentação, a presença da subjetividade se materializa através desses elementos linguístico-discursivos presentes no próprio gênero.

Diante desses resultados, concordamos com a afirmação de Espíndola (2004) sobre a argumentação na língua, de que não apenas a língua, mas também o seu uso são essencialmente argumentativos, uma vez que quando se interage por meio da linguagem, é sempre em função de atingir determinados fins e é, justamente, por esse motivo que o falante busca a todo instante direcionar o seu discurso para ser interpretado conforme o que se diz (ou se pretende dizer).

\section{REFERÊNCIAS}

BAKHTIN, Mikhail. Estética da criação verbal. 3 ed. São Paulo: Martins Fontes, 2000 [1979]. BAKHTIN, Mikhail. Estética da criação verbal. 5a . ed. São Paulo: WMF Martins Fontes, 2010. BELTRÃO, Odacir; BELTRÃO, Mariúsa. Correspondência, linguagem e comunicação: oficial, comercial, bancária, particular. 23 ed. São Paulo: Atlas, 2005.

CASTILHO, A. T.; CASTILHO, C. M. M de. Advérbios modalizadores. In: ILARI, Rodolfo (Org.). Gramática do português falado. 2. ed. Campinas: Editora da Unicamp, 1993. v. II.

CERVONI, Jean. A Enunciação. São Paulo: Ática, 1989.

DUCROT, Oswald. Polifonia y Argumentación: Conferencias del Seminario Teoria de la Argumentación y Análisis del Discurso. Cali: Universidad del Valle, 1988.

SP: Pontes, 1987.

Oswald. O dizer e o dito. Revisão técnica da tradução Eduardo Guimarães. Campinas

ESPÍNDOLA, Lucienne. A entrevista: um olhar argumentativo. João Pessoa: EDUFPB, 2004.

GALDINO, Monique Cezar Merêncio. As entrelinhas do contrato: uma análise sociossubjetiva dos parâmetros de produção e de recepscão do gênero. 2014. Dissertação (Mestrado em Linguística) Universidade Federal da Paraíba - UFPB, Paraíba, 2014.

GASPARINI, Diogenes. Direito administrativo. 12. ed. ver. e atual. São Paulo: Saraiva, 2007.

GODOY, Arilda Schimidt. Pesquisa Qualitativa. Revista de Administração de Empresas, São Paulo, v. 35, n. 3, Mai./Jun., 1995.

HAGGAR, Thomas R. Legal Drafting: in a Nutshell. St. Paul, Estados Unidos: West Publishing Co., 1996.

KOCH, Ingedore Grunfeld Villaça. Argumentação e linguagem. 12. ed. São Paulo: Cortez, 2009. 
MARCUSCHI, L. Antônio. Produção textual, análise de gêneros e compreensão. $3^{\mathrm{a}}$ Ed. São Paulo: ed. Parábola Editorial, 2008.

MEDEIROS, João Bosco. Correspondência: técnicas de comunicação criativa. 18. ed. São Paulo: Atlas, 2006.

MEIRELLES, Hely Lopes. Direito Administrativo Brasileiro. 33. ed. São Paulo: Malheiros Editores, 1990.

NASCIMENTO, Erivaldo Pereira do. Jogando com as vozes do outro: argumentação na notícia jornalística. João Pessoa: Editora Universitária UFPB, 2009.

, Erivaldo Pereira do. A modalização deôntica e suas peculiaridades semântico-pragmáticas. Fórum Linguístico, Florianópolis, 2010.

NASCIMENTO, Erivaldo Pereira do; SILVA, Joseli Maria da. O fenômeno da modalização: estratégia semântico-argumentativa e pragmática. In: NASCIMENTO, Erivaldo Pereira do (org.). Argumentação na Redação Comercial e Oficial: Estratégias semântico-discursivas em gêneros formulaicos. João Pessoa: Editora Universitária da UFPB, 2012.

NEVES, Maria Helena de Moura. Texto e gramática. 1. ed. São Paulo: Contexto, 2010.

STUTTERHEIM, Christiane von. Modality: Function and Form Discourse. In: DITTMAR, Norbert; REICH, Astrid. Modality in Language Acquisition. Berlin; New York: Walter de Gruyter, 1993.

Submetido em 20/12/2019

Aceito em 31/01/2020

Publicado em 14/02/2020 